\title{
Research on the Application of Natural Daylighting System in Office Space
}

\author{
Zhang $\mathrm{Wu}^{1}$ Chulsoo Kim²,*
}

\author{
${ }^{1}$ Marine Convergence, Pukyung University, Busan, South Korea \\ ${ }^{2}$ Division of Industrial Design, Pukyung University, Busan, South Korea \\ *Corresponding author.Email:852755086@qq.com
}

\begin{abstract}
Natural light is the most important element in the natural environment and a valuable asset that nature has given us. In architecture design. In architectural design, if the natural light can be used scientifically and reasonably, it can not only effectively reduce energy consumption such as lighting and heating and air conditioning, but also improve lighting conditions of the building and provide a better office environment. This study provides an in-depth understanding of natural day lighting and application, which can solve the problem of large-scale urban development (population intensive and intensive building, high-rise buildings) and create a more comfortable urban environment. The future living space will surpass simple building function, seek human physical and psychological stability, and maintain a comfortable life, because a good light environment is basis for ensuring comfort of visual function, directly affecting attention, thereby affecting labor production, efficiency and vision health.
\end{abstract}

\section{Keywords: natural day lighting, healing, office space, work efficiency, environmental protection}

\section{INTRODUCTION}

\section{A. Research background}

Light generally provides necessary living environment for our activities, an important design factor for creating atmosphere in office space. It has its characteristics in composition of office space. In addition, it is also light that plays a decisive role in plant growth. Light is an important factor in plant growth and development.

Stress is the internal tension that is caused by externally applied pressure from all external stimuli that can break the balance of the body. In the modern sense, the balance between physical, psychological, mental stress and internal protective resistance of the external environment is broken, and the protection ability of human individuals is impaired and deformed, including physical and mental symptoms.

Biosilic design, inspired by nature, is popular. A book from Edward Winson, a professor at Harvard University in the United States, also mentioned Biophilic designs. People are dependent on ecology. (Biosilic design) means love for life and system". Biometric Design is a design approach that links nature to us and is a project that many of the most creative companies in the world are advancing. Biophilic design is. It is based on the design that human beings are naturally attracted to nature. From the natural materials, the design materials are transported in the urban design to achieve the healing function and bring new impetus to the city.

It is based on the Aaronic idea that human beings are naturally attracted to nature, a life-respecting design that inspires and heals the city with the design material pattern inspired by nature. ${ }^{1}$

Today, $47 \%$ of office space has no day lighting ${ }^{2}$. Most of the natural lighting entering room through lighting window has been decided at the design stage of the building. In design stage of office space, it should focus on adjusting lighting and proper lighting installation $^{3}$. The use of natural lighting can save energy and protect environment, while more conducive to physical and mental health of office workers, making office space a healing space.

\section{B. Research necessity}

Office space refers to workplace provided for office. At present, enterprises, units, and personal office space all pay attention to the design of office space. This not only has the stimulating factors of market competition, but also the market means to open up market to increase output value, at the same time, it improves working environment of employees, so that people in a busy

JoongAng Ilbo Design, 2019.4.19

Jing ru, office environment design, March 13, 2018

Choi Sung-hyeon, Kim Dae-hee, Tianjin Hee, Revised

Interior Design, 2011, p.188. 
working environment can get healing from natural ecological environment. Natural lighting is from the natural environment, and it is also the most direct way. Therefore, natural lighting is added to the design of office space to improve work efficiency and employee satisfaction. Under reasonable light, it is beneficial to people to feel psychological balance and stability.

\section{NATURAL DAY LIGHTING IN OFFICE} SPACE

Under good natural light, the human eye can carry out effective visual work. Moreover, natural day lighting is more conducive to the ecological environment while utilizing green resources, and is one of the ways to achieve sustainable building. (See "Fig. $1 ")$

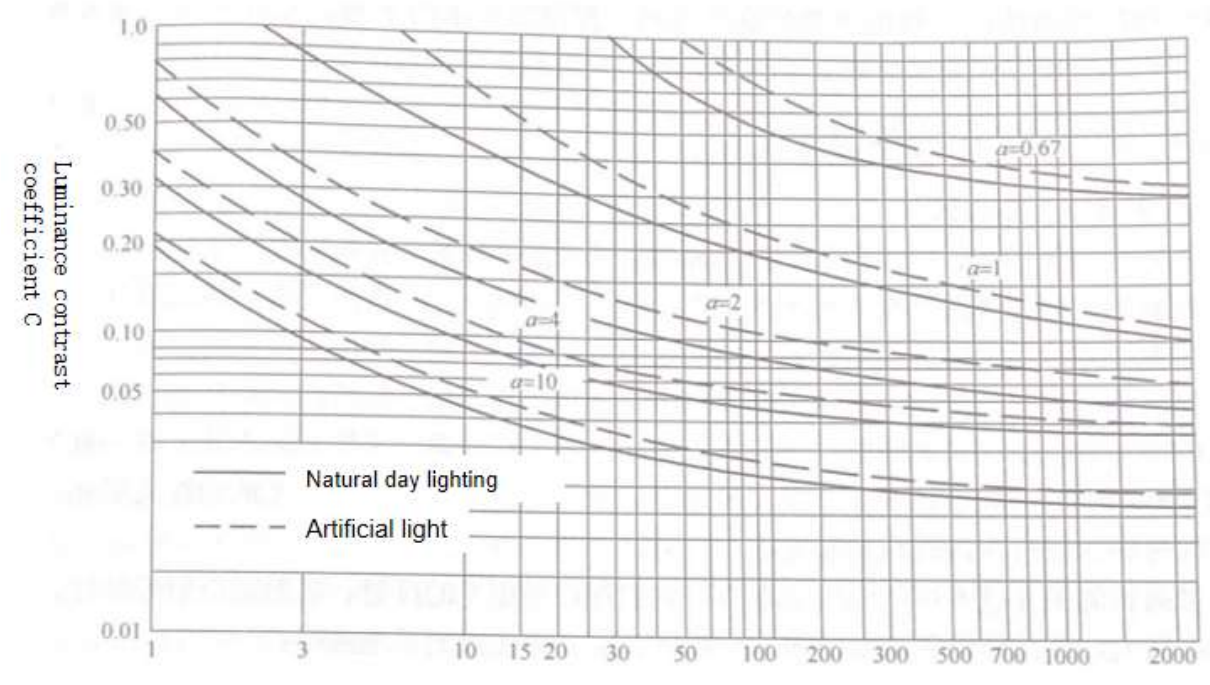

Fig. 1. Luminance contrast coefficient.

Humans are suitable to work in bright places, such as fluorescent lamps with high color temperature. The activity of autonomic nerves is activated by the bright light of fluorescent lamps, which increases the activity with the mental and physical tension. ${ }^{4}$

The physical phenomena such as absorption, refraction, reflection, transmission, and diffusion occur depending on the brightness of light and the characteristics of the trans missive body through which natural light is introduced. Emphasize the image of space (Kim, 1995). ${ }^{5}$

Emotional stability can be induced by creating a comfortable and warm atmosphere when natural light and physical phenomena occur. The brightness contrast of the light produces the boundaries and shadows of the area. The indirect spatial segmentation caused by the difference in brightness of light can sense and feel the depth of space and create a good environment for the development of spatial cognition.

\footnotetext{
4 Hyun-Bea You, Basic Study of Space Design for Healing, 210.10 .

http://www.dbpia.co.kr/journal/articleDetail?nodeId=NODE0732179 5 Journal of the Korea Institute of Spatial Design, Vol.13 No.1 . p. 21
}

\section{A. Natural lighting}

The sun light is a green light source, which has high light efficiency, good visual effect, and is not easy to cause visual fatigue. The human eye is also accustomed to seeing things under natural lighting. "Fig 2" and "Fig. 3 " shows the visual effect curve when the discrimination probability is $95 \%$. It can be seen from the graph that the human eye has higher sensitivity under natural lighting than artificial light. Especially in the case of ground illumination or when viewing small objects, this visual difference is more significant. ${ }^{6}$

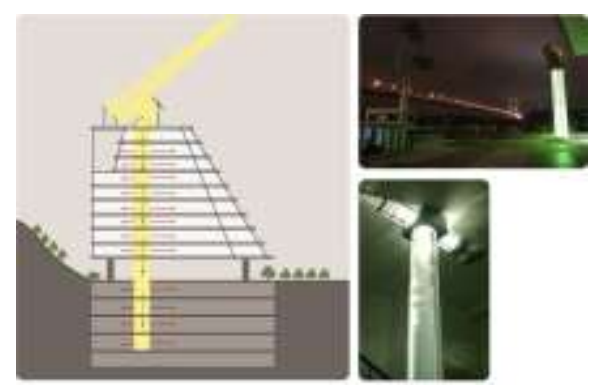

Fig. 2. Natural lighting system $1^{7}$.

\footnotetext{
6 "Basic Theory of Green Buildings", China Building Industry Press, 2015.10, p.108.

7 Whilkor: http://www.whilkor.com/sub/sub6_3.php
} 
Daytime light can promote the secretion of Melatonin at night, help sleep, and light can also activate the brain. It can increase incidence of depression, so it can treat depression. Light naturally regulates physiology rhythm, eliminates body imbalance, and has a positive effect on memory field. Not only that, vitamin D synthesized by light can prevent osteoporosis, and it also has healing effects of prostate cancer, colon cancer, and breast cancer. For light therapy, the possibility of right epidermis is endless. If we conduct in-depth research on this, we can be free from pain and rely on the sun to protect our body and mind $^{8}$.

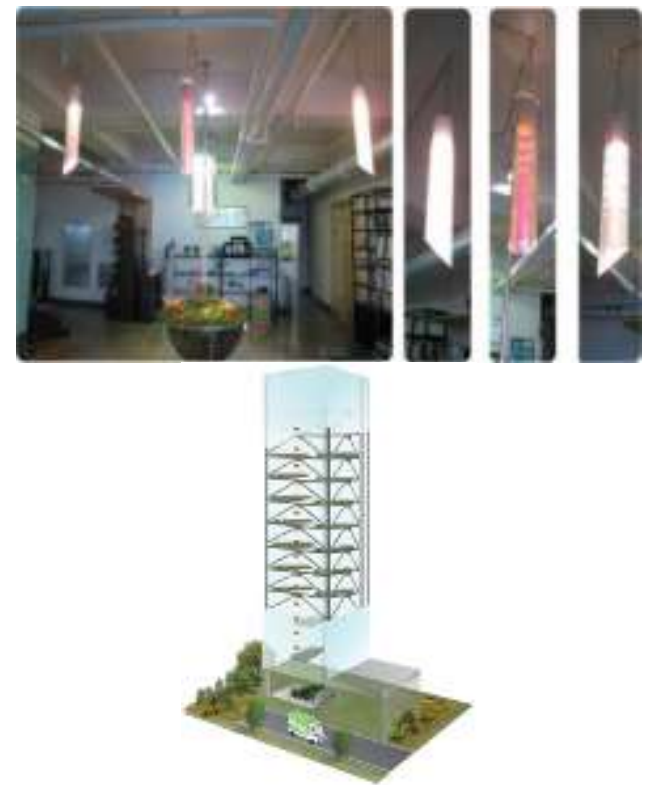

Fig. 3. Natural lighting system 2 natural lighting system $2^{9}$.

\section{B. Office environment natural lighting system}

A product made by placing a prismatic film into a tube is a device that uniformly transfers and disperses sunlight like a stream of water.

Natural day lighting systems can attract this kind of solar energy to where it is needed and use it (solar cells, solar boilers, underground, indoors, etc.) to solve the rapid development of large cities (population intensive and intensive buildings, high-rise buildings, litigation dispute) to create a more comfortable urban environment. From this point, the future living space will surpass the simple architectural function, seek human physical and psychological stability, and maintain a comfortable life.

Li Qingxi: "Research on the characteristics of treatment centers that introduce the concept of natural treatment", National University Graduate School, Shi Nong, 2010, p73.

$9 \quad$ Whilkor: http://www.whilkor.com/sub/sub6_3.php

\section{Natural light effect}

Natural light is a technology that draws such solar energy to the desired place (solar cell, solar boiler, underground, indoor, etc.)

It can solve the issue of solitude conflict, which is the problem of large cities that have achieved industrial development (due to the concentration of population and the concentration and building of buildings).In particular, the recent rapid entry into an aging society will require a different level of housing patterns and communication between members of society.

In the context of improving the quality of life for a healthy society, the residential space of the future goes beyond simple building functions to the elderly and The focus will be on promoting physical and psychological stability of the inmates and maintaining a pleasant life.

- 1) Reduction of lighting energy and environmental improvement in construction and industrial facilities. Increased work efficiency by improving the visual environment in the office space: $16 \%$ improvement in productivity (Seattle City Hall report). Productivity increase of factory, defective product rate decrease by $20 \%$.

- 2) Low carbon green growth and realization of green environment; Cooling and heating load reduction: Cooling 15\%, Heating 30\%; 20-35\% reduction in energy consumption and maintenance costs

- 3) National health promotion, education and health environment improvement; Excellent color rendering provides a pleasant environment and reduces eye fatigue; Reduced incidence of seasonal depression (SAD), improved academic environment $(7-26 \%)^{10}$

\section{THE NECESSITY OF NATURAL LIGHTING APPLICATION IN OFFICE SPACE}

\section{A. Healing function}

The cure here is different from the post-trauma stabilization therapy by general physical therapy, which is close to the concept of preventing mental stress and maintaining good health ${ }^{11}$. People have a close relationship with natural environment. The natural environment requires a fresh air environment and a green visual environment. Therefore, we have chosen natural lighting in natural environment elements, and designed the psychological hint of using natural lighting to apply a natural environment in the office

10 Whilkor company:http://www.whilkor.com/sub/sub6_3.php

11 Ko Jong Hoon, A Study on the Conception and Case study of Healing Design, No.43, 2015, p. 14 
space, reducing the staff's office pressure, thus alleviating the role of psychotherapy and psychological comfort. (See "Fig. 4")

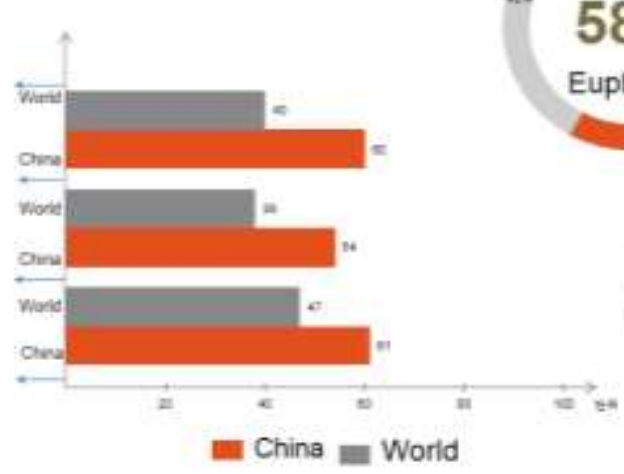

Euphoria plays a very important role in the workplace experience.

Fig. 4. The effect of natural light on 1.

It is understood that people sitting next to the window are $7 \%$ more efficient than other staff. The study found that in an office designed with natural elements, employees' happiness is generally $15 \%$ higher, creativity is $15 \%$ higher, work efficiency is $6 \%$ higher, cognitive ability is increased by $26 \%$, and sick leave time is reduced by $30 \%$. In other words, even if employees return home, the benefits in the office continue.

\section{B. Green energy control function}

The natural light and natural day lighting system of the natural environment involved in this study are all reasonable use of natural light. The natural day lighting system is a natural light introduction device such as a solar panel or a light pipe.

In "Fig. 2": Light reflection in the building and secondary reflection of light through which, it is ensured that the indoor hanging light is uniform, thereby reducing the consumption of artificial light, that is, achieving energy saving.

TABLE I. THE COMMONALITY OF COLOR SENSE ${ }^{12}$

\begin{tabular}{|c|c|c|c|c|c|c|c|c|}
\hline \multirow{2}{*}{$\begin{array}{l}\begin{array}{c}\text { Psychological } \\
\text { feeling }\end{array} \\
\begin{array}{l}\text { Sense of light } \\
\text { and shade }\end{array} \\
\end{array}$} & \multirow{2}{*}{$\begin{array}{l}\text { Left trend } \\
\text { light }\end{array}$} & \multicolumn{2}{|c|}{ Positive color } & \multirow{2}{*}{$\begin{array}{l}\text { Neutral } \\
\text { color }\end{array}$} & \multicolumn{3}{|c|}{ Negative color } & \multirow{2}{*}{\begin{tabular}{|l|} 
Right trend \\
dark \\
\end{tabular}} \\
\hline & & orange & Green, red & & & & black & \\
\hline Cold and hot & warm & red & yellow & & & & white & nice and cool \\
\hline $\begin{array}{l}\text { Swelling and } \\
\text { shrinkage }\end{array}$ & expand & orange & yellow & & & & & contract \\
\hline $\begin{array}{l}\text { distance } \\
\text { perception }\end{array}$ & near & orange & red & & & & & far \\
\hline weight sense & $\begin{array}{|lr|}\text { slim and } \\
\text { graceful }\end{array}$ & orange & red & & & & black & heavy \\
\hline Excitement & exciting & orange red & $\begin{array}{l}\text { Yellow, green, } \\
\text { red and purple }\end{array}$ & & green & blueness & black & heavy \\
\hline
\end{tabular}

12 "Basic Theory of Green Architecture", China Construction Industry Press, 2015.10, p.106. 


\section{Practical features}

A good light environment is the basis for ensuring comfort of visual function, which directly affects attention, thus affecting labor productivity and vision health. The color comes from light. In the working environment, natural light reflection not only allows people to directly see things, but also allows people to see the beauty of things through color, as well as personal emotional distractions. As shown in Table 3

Bright colors such as yellow and red seen from table helps people to attract attention to outside to increase activation, which helps people to attract attention to the outside to increase activation, help people activate agility and extroversion, and help muscle exercise and function, of which will be suitable for physical labor and entertainment. Cool colors such as gray, blue and green plus low-light illumination make the energy disperse, people can not concentrate better. For difficult visual tasks and mental work, this environment is suitable for sedentary, high requirements for eye and brain work Places, such as office space, research rooms, etc.

\section{Other applications}

Indoor space has natural light, more suitable for plant growth, bring the green nature into the space of work to make the narrow office space more rich interest, green plants can also let people in the eyes tired when they appreciate their eyes and mood are relaxed, to eliminate fatigue also has a good effect.

\section{CONCLUSION}

Through this study, you can enjoy the healing effect of living in the environment of nature as much as it comes from nature. The use of natural light in the interior of the building is the most comfortable condition of healing. It was found that the effect of healing can be realized by connecting with nature, which is the basis of healing, and using natural materials to create a living space. (See "Fig. 5")

\section{Indoor Landscape Design}

1.Air pollen

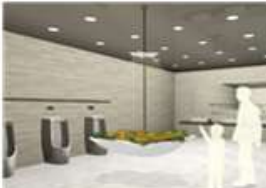

It is an ideal product where indoor toilet space and floor cleaning are essential, and it is a product that can grow healthy plants linked with our incorruptible soil and fiberoptic natural light system.
2.Wall Land scape
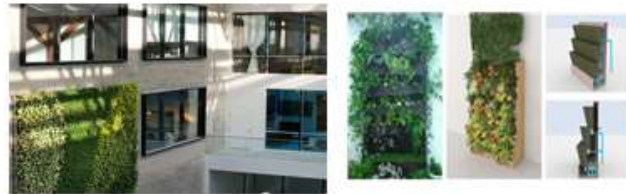

It is a landscape method that takes up relatively little space and is highly effective.

Fig. 5. Indoor landscape design.

When people have possibility of physical, visual, and psychological activities, they feel a sense of space. Unlike an object with a certain shape, space is a spacetime continuum in which people living in it move with flexibility. People need a wide space, and they also need to be protected in a closed space that gives people a sense of stability. In the process of constructing indoor space, in order to meet the psychological needs of people, it is necessary to properly arrange a wide space and space. In the office space of office workers, natural lighting is used as a decoration element, and proper adjustment of strength can reduce eye fatigue, more conducive to the physical and mental health of the staff while improving work efficiency.

\section{References}

[1] Choi Sung-hyeon, Kim Dae-hee, Tianjin Hee, Revised Interior Design, 2011

[2] Lee Kyung-heei: research on the characteristics of treatment center by introducing the concept of natural therapy, graduate thesis of national university, 2010,

[3] Jing ru, office environment design, March 13, 2018

[4] "Basic Theory of Green Architecture", China Construction Industry Press, 2015.10,

[5] Whilkor company:http://www.whilkor.com/sub/sub6_3.php

[6] JoongAng Ilbo Design , 2019.4.19

[7] Hyun-Bea You , Basic Study of Space Design for Healing, Pukyung University. http://www.dbpia.co.kr/journal/articleDetail?nodeId=NODE073 21790

[8] Journal of the Korea Institute of Spatial Design, Vol.13 No.1 